\section{Convention on Biological Diversity, CoP V-moving from concepts to action?}

The maturation of the Convention on Biological Diversity (CBD) over the six and a half years since it came into force has been marked by a growing understanding of the niche of this Convention and its relationship with other international agreements and fora. Furthermore, confidence in the strength of the Convention is reflected in its growing ability to address challenging international issues relating to globalization, international trade and economics, indigenous rights, food security and poverty alleviation. However, questions remain over the ability of the Convention to move beyond words to action. Much of this was evident when the Fifth Conference of the Parties (CoP) of the CBD met at the United Nations Environment Programme (UNEP) headquarters, at Gigiri, Nairobi between 15 and 26 May 2000.

With a total of 1500 delegates, representing over 156 governments, as well as non-governmental organizations (NGOs) and other observing institutions, there was a strong sense of activity throughout the UNEP buildings, and the main working group meetings were augmented by numerous displays, side events and workshops. Despite a smaller turnout than was perhaps expected, the meeting was dynamic and businesslike, with notably increased efficiency in negotiations and decision-making than at previous CoPs. Fauna \& Flora International (FFI) was represented by two staff during the meeting, with a remit to follow proceedings in the key sessions. In addition, we were there to meet with a range of collaborating governments and partner institutions, because, as usual, much of the real discussion took place away from the official conference halls.

The areas of greatest impact, controversy-and arguably success-for the meeting related to biotechnology (and consequently biosafety), agrobiodiversity, access to genetic resources and traditional knowledge, all of which lie at an important interface between biodiversity and the spheres of politics and commerce. Reflecting this focus, those lobbying on issues relating to indigenous rights, biotechnology and bioprospecting were by far the most vociferous groups at the meeting. The second week of the meeting was dominated by the Cartagena Protocol on Biosafety which provides legally-binding measures to promote and monitor transfer, handling and use of 'living modified organisms', based on a precautionary principle, through prior informed consent of receiving countries. A high-level ministerial discussion focused on the capacity-building and information-sharing needs to support the eventual enforcement of this Protocol, and this was followed by an official signing ceremony. By the end of the week, 68 nations had signed this Protocol, and it is currently hoped that prompt ratification will allow the Protocol to come into force by 2002.

Elsewhere in the meeting a range of priority issues, programmes of work and cross-cutting (i.e. overarching) issues were discussed, along with continued negotiations on the operations of the Convention. While the programmes of work on inland waters and marine and coastal ecosystems (including the threat of coral bleaching) raised relatively little discussion, the work on forest ecosystems resulted in protracted negotiations. Although many nations accepted the recommendations that the programme of work should move from research to action, this was not clearly incorporated in the final wording of the decision. Furthermore, the opportunity for broader participation on the issue of forest policy prior to the next CoP through an ad hoc openended working group was abandoned in favour of a small expert group. However, it was later revealed that through lack of congruence with the workshop on financial mechanisms, money was not available from the core budget to support the workings of this group. From FFI's viewpoint, the decisions made represent a missed opportunity to take the lead on issues relating to forest loss, with the CBD now relying on action from other institutions, such as the Inter-governmental Forum on Forests and the newly formed UN Forum on Forests. This effectively undermines the credibility of the CBD with regard to an issue that remains, arguably, one of the greatest threats to overall biodiversity loss. However, it was pleasing to see that the UK delegation's case to include mention of the bushmeat issue in relation to non-timber forest products was incorporated in the final decision.

Consideration of work on the theme of agrobiodiversity led to mention of the role of farmers in protecting the genetic diversity of crops and livestock, and also the establishment of an initiative to focus on pollinators and their role in agricultural systems. The main area of debate, however, related again to biotechnology, focusing on the use of Genetic Use Restriction Technologies (GURTS) including so-called 'terminator technology' (which induces sterility in the 2nd generation), and trait-specific technologies, which many consider harmful to food security in the developing world. In its final decision, the parties accepted the recommendation that the precautionary principle should be adopted with regard to GURTs, and called for a moratorium 
on commercial use and field-based trials ahead of appropriate scientific assessments, including studies of their likely impacts in relation to biodiversity and socio-economic factors.

The debates on access and benefit sharing of genetic resources and Article $8 \mathbf{j}$ (relating to traditional knowledge of biodiversity) demonstrated that the Convention upholds one of its three central principles-namely to promote equity and fair sharing of genetic resources. The negotiations on traditional use, which involved greater participation of indigenous groups than previously, clearly demonstrated the relationship between biodiversity, culture, and individual rights to biological and genetic resources. Discussions on access and benefit sharing, although protracted, reached agreement on prior informed consent mechanisms, and mutually agreed terms for international access to genetic resources. The status of material in ex situ collections was also discussed, along with the need for regulation in receiving countries as well as source countries of genetic resources. The great potential of international markets and trade to influence access to biodiversity has become clear from recent WTO negotiations over the agreement on TradeRelated Aspects of Intellectual Property Rights (TRIPS), which considers intellectual property rights relating to genetic resources, and the potential for patenting of life forms. In the final decision, parties called on the WTO to acknowledge CBD provisions within further development of the TRIPS agreement.

A new thematic work programme on the biodiversity of dry and subhumid lands was adopted, with clear relationships to sustainable use, agrobiodiversity and secure livelihoods, and the Convention to Combat Desertification. In addition, decisions were taken on cross-cutting issues and priority issues including sustainable use, biodiversity and tourism, alien species, incentive measures, indicators and monitoring, impact assessment, the ecosystem approach, education and awareness, the Global Taxonomy Initiative and the Global Strategy for Plant Conservation. A number of notable issues arose from the discussions on these topics.

- Whilst the priority issue of preventing and mitigating threats associated with alien species has moved forward to a full review and call for case studies, suggestions to establish a protocol on alien species, and the obligations this would engender, were rejected.

- The ecosystem approach was adopted as a central tenet of the convention, despite some reservations about the principles laid out in the supporting paper. It was felt that while the concept of a holistic approach to conservation was accepted, it was difficult to see how this concept would be applied within an implementation framework. It was understood that further development of the ecosystem approach would rely on analysis of case studies to allow the current framework to be revised.

- Consideration of the need to harmonize approaches to identification and monitoring of biodiversity between parties led to the decision to develop a set of principles for national level monitoring, supported by lists of standard questions and potential indicators.

- The debate on sustainable use as a cross-cutting issue proposed relating this to the ecosystem approach, and promoted links to the IUCN Sustainable Use Initiative. The specific issue concerning the relationship between biodiversity and tourism was discussed, and the need for case studies, and crosssectoral involvement (including the tourism industry) in developing this theme further was noted.

- With support for the continued development of the Global Taxonomy Initiative (GTI) and the possible establishment of a Global Strategy for Plant Conservation Strategy (GSPC) there are clearly new focuses for work under the CBD. First, the assessments of national taxonomic knowledge and expertise under the GTI, and second, the consideration of appropriate plant-related conservation strategies under the GSPC.

Despite the growing mainstreaming of biodiversity issues, and a conference dealing with issues relating to international trade and economic development, there was a noticeable gap in participation in the CoP from one significant sector-the business community. Apart from the presence of biotechnology companies, business and industry representation was relatively poor. While the need to involve the business community in the workings of the CBD was discussed in relation to biotechnology, tourism and, most tellingly, finance of the Convention, there was little involvement from the businesses in question in such debates.

Given the recognized benefits of wide-ranging stakeholder involvement in the biodiversity planning process, there is a clear requirement to encourage business participation at such events, and understand how this sector can relate more effectively to the policy debate on biodiversity. In support of increased business involvement, the UK Government delegation convened a workshop focusing on the roles of participation and partnership in biodiversity planning, with invited speakers from FFI and BP-Amoco. Such a way forward marks a newfound dialogue between biodiversity policy makers and industry, and demonstrates how business can be engaged in the broader biodiversity debate. If the CBD is committed to mainstreaming biodiversity and tackling broader economic and political issues that affect biodiversity in the 
global marketplace, an effective dialogue with business would appear to be a crucial step in the maturity of the Convention, and in assisting the essential transition from policy generation to implementation.

Further details of CBD decisions are available on the Web at www.biodiv.org and www.iisd.ca/linkages/
Dr Abigail Entwistle

Senior Scientist

Fauna \& Flora International

Great Eastem House, Tenison Road

Contbridge CBI 2TT, UK 